\title{
The Impact of Human Lipoaspirate and Adipose Tissue-Derived Stem Cells Contact Culture on Breast Cancer Cells: Implications in Breast Reconstruction
}

\author{
Asim Ejaz, Katherine S. Yang, Kaushik P. Venkatesh, Somaiah Chinnapaka, Lauren E. Kokai and \\ J. Peter Rubin * \\ Department of Plastic Surgery, University of Pittsburgh, Pittsburgh, PA 15261, USA; ejaza@upmc.edu (A.E.); \\ ksy6@pitt.edu (K.S.Y.); kpv5@pitt.edu (K.P.V.); chinnapakas@upmc.edu (S.C.); kokail@upmc.edu (L.E.K.) \\ * Correspondence: rubinjp@upmc.edu; Tel.: +1-412-383-8080; Fax: +1-412-383-9053
}

Received: 27 August 2020; Accepted: 27 November 2020; Published: 1 December 2020

\begin{abstract}
Background: Autologous fat transfer in the form of lipoaspirates for the reconstruction of the breast after breast cancer surgery is a commonly used procedure in plastic surgery. However, concerns regarding the oncologic risk of nutrient-rich fat tissue are widely debated. Previous studies have primarily focused on studying the interaction between adipose-derived stem cells (ASCs) and breast cancer cells. Methods: In this study, we performed a comprehensive analysis of the paracrineand contact-based interactions between lipoaspirates, ASCs and breast cancer cell lines. An inverted flask culture method was used to study the contact-based interaction between lipoaspirates and breast cancer cells, while GFP-expressing breast cancer cell lines were generated to study the cell-cell contact interaction with ASCs. Three different human breast cancer cell lines, MCF-7, MDA-MB-231 and BT-474, were studied. We analyzed the impact of these interactions on the proliferation, cell cycle and epithelial-to-mesenchymal (EMT) transition of the breast cancer cells. Results: Our results revealed that both lipoaspirates and ASCs do not increase the proliferation rate of the breast cancer cells either through paracrine- or contact-dependent interactions. We observed that lipoaspirates selectively inhibit the proliferation of MCF-7 cells in contact co-culture, driven by the retinoblastoma $(\mathrm{Rb})$ protein activity mediating cell cycle arrest. Additionally, ASCs inhibited MDA-MB-231 breast cancer cell proliferation in cell-cell contact-dependent interactions. Quantitative real-time PCR revealed no significant increase in the EMT-related genes in breast cancer cells upon co-culture with ASCs. Conclusion: In conclusion, this study provides evidence of the non-oncogenic character of lipoaspirates and supports the safety of clinical fat grafting in breast reconstruction after oncological surgical procedures. In vivo studies in appropriate animal models and long-term post-operative clinical data from patients are essential to reach the final safety recommendations.
\end{abstract}

Keywords: adipose-derived stem cells; lipoaspirates; breast cancer cells; cell cycle and proliferation

\section{Introduction}

The global burden of breast cancer surpasses all other cancers, and is the most common malignancy in females [1]. Advancements in diagnostic and therapeutic approaches have resulted in improved survival rates. However, breast-conserving therapies or mastectomies are associated with disfiguring and stigmatizing outcomes for patients. Autologous fat transfer (AFT), pioneered by Coleman in the late 1990s, is an invaluable tool used routinely by plastic surgeons for tissue reconstruction and augmentation [2,3], and AFT for breast augmentation and reconstruction has become increasingly popular [4].

Fat tissue abundance, as well as the autologous nature and minimal invasiveness of the procedure, are the attractive factors supporting the broader utilization of AFT. In addition to high patient and 
surgeon satisfaction, AFT is associated with improved scar healing, and reductions in pain and fibrosis following oncological radiation therapy [1,5-11]. Adipose-derived stem cells (ASCs) residing within the adipose tissue likely play a key role in maintaining graft volume retention and regenerative functions [12]. ASCs contribute to these functions by secreting a plethora of paracrine factors that promote angiogenesis, cell migration and differentiation [2].

Despite the clinical benefits, AFT is associated with a few addressable drawbacks, such as graft resorption and interference with diagnostic tissue imaging. More importantly, the greatest concern associated with AFT is the possibility of cancer-promoting interactions between paracrine-rich adipose tissue and remnant tumor cells in the tumor bed, which can result in locoregional tumor recurrence. This concern has been supported by results from recent studies showing that in vitro expanded ASCs enhance breast cancer cell growth and migration in vitro and in rodent models [13-15]. Interactions between ASCs and breast cancer cells increase cytokine production and malignant transformation of the breast cancer cells via adipsin and Src/Sox/miR-302b mediated signaling [14,16]. Further, a recent study employing in vitro differentiated adipocytes showed that fatty acids released through adipocyte lipolysis drive breast cancer cell proliferation and differentiation [17]. Furthermore, breast cancer cells induce morphological and functional changes in ASCs, altering them to function as cancer-associated fibroblasts. Such cells promote tumor progression, angiogenesis and endothelial-to-mesenchymal transition (EMT), a key event involved in tumor metastasis [18]. Similarly, Rowan et al. demonstrated enhanced kidney, lung and spleen metastasis upon the injection of ASCs together with breast cancer cells [19].

However, most studies that suggest ASCs increase tumor progression use co-culture or in vivo models, which is inconsistent with the clinical scenario composed of intact adipose parcels injected into a large tissue bed for breast reconstruction. In addition, most of the studies relied on in vitro differentiated adipocytes or paracrine interactions between cells as experimental models $[14,16,17,20-22]$. On the other hand, a recent study from our lab demonstrated the oncological safety of lipofilling as part of the surgical platform for breast reconstruction after cancer therapy. We had used a clinically relevant animal model and reported no increase in tumor size, proliferation, histological grade, or metastatic spread [23]. These results are supported by the meta-analysis of clinical results, in which a long-term (5 year) follow up study of AFT involving 587 total patients (287 AFT and 300 controls, matched for age, type of oncological surgery, tumor invasiveness, and disease stage) showed no increase in locoregional recurrence of cancer. Rather, a lower but non-significant decrease was observed [1].

This study aimed to provide comprehensive insight into the interactions between breast cancer cells, lipoaspirates and ASCs. To our knowledge, this is the first example of the paracrine and contact co-culturing of breast cancer cells with lipoaspirate or ASCs from the same donors. We analyzed the effects of these interactions on the proliferation of breast cancer cells and analyzed the underlying mechanisms.

\section{Results}

\subsection{Lipoaspirate Contact Co-Culture Reduces the Proliferation Rate of Breast Cancer Cell Lines}

An important concern pertaining to the use of fat grafts for the post-oncological reconstruction of the breast is the possible aggravation of the remnant breast cancer cells upon interaction with transferred autologous fat in the form of lipoaspirates. Although several clinical and animal studies have demonstrated similar or lower incidences of cancer recurrence from post-oncological reconstruction with fat graft compared to other means of breast reconstruction $[1,23,24]$, there still exist substantial data indicating a pro-oncogenic role of lipoaspirates and adipose-derived stem cells $[14,16,20,22]$. To the best of our knowledge, the most clinically relevant scenario has yet to be studied, i.e., a direct cell-cell contact interaction between lipoaspirates and breast cancer cells. In addition, studies investigating the interaction between adipocytes and breast cancer cells either rely on in vitro differentiated ASCs $[14,17,21]$ or have used transwell or a 6-well co-culture system [14,20]. One drawback of using 
transwell or a 6-well co-culture system is that the lower density adipocytes float and may be damaged by hypoxia (Figure 1A,B). These damaged adipocytes release inflammatory cytokines that may change the co-culture milieu. To overcome this technical issue and simulate the clinical scenario of breast cancer cells and lipoaspirate interaction, we performed a paracrine and contact co-culture in a closed flask setting, as shown in (Figure 1C,D), respectively.

\section{Experimental design}

A

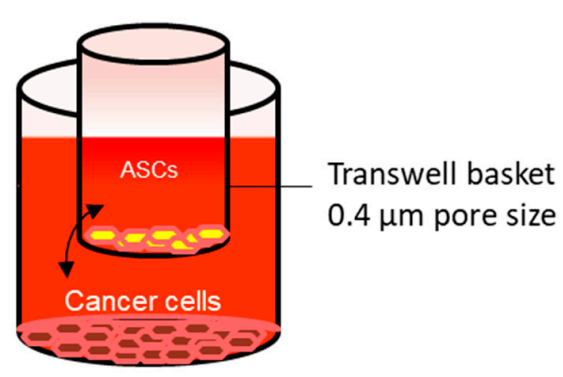

C

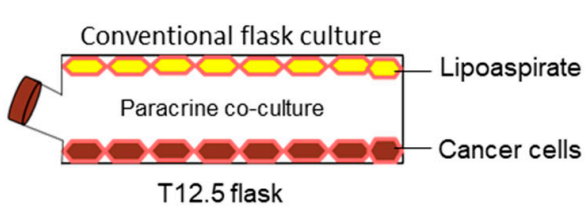

B

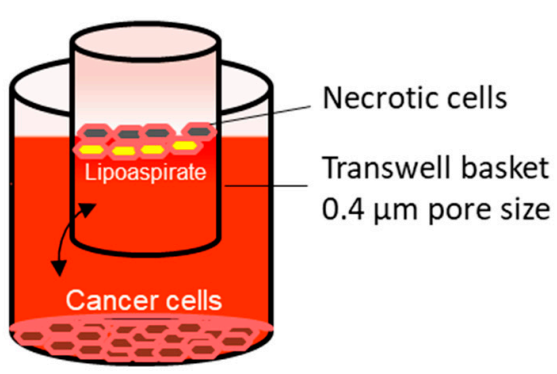

D

Flask flip
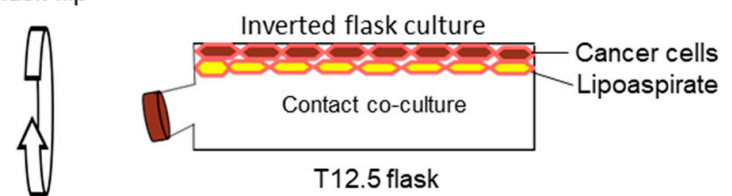

T12.5 flask

Figure 1. Contact and paracrine co-culture experimental design. (A) Paracrine culture setup of cancer cells with adipose-derived stem cells (ASCs) using 6-well transwell plates. (B) Paracrine culture setup of cancer cells with lipoaspirates. (C,D) Modified paracrine (C) and contact (D) co-culture of cancer cells with lipoaspirate using T12.5 $\mathrm{cm}^{2}$ flask. (E) Comparison of MCF-7 cells proliferation in conventional and inverted flask culture $(n=4)$. ns = non-significant.

Utilizing the buoyancy property of lipoaspirate, we performed a conventional culture where, afte seeding the breast cancer cells and adding lipoaspirate, we incubated the flask using conventional methods that enable the cancer cells and lipoaspirate to stay apart, thus allowing only the paracrine interaction (Figure 1C). To achieve contact between lipoaspirates and breast cancer cells, we incubated the flasks in an inverted position (Figure 1D) which enabled the floating lipoaspirates to come into contact with breast cancer cells. We observed similar growth kinetics of MCF-7 in our conventional and inverted flask culture settings, supporting the utilization of these culture settings for co-culture studies (Figure 1E).

The contact co-culture of lipoaspirates resulted in a significant decrease in the proliferation rate of the MCF-7 cells, while the MDA-MB 231 cells and BT-474 also showed a lower but 
non-significant proliferation rate on the contact culture (Figure 2A-C). Paracrine co-culture of lipoaspirate showed no effect on proliferation of breast cancer cell lines when compared to monocultured cells (Figure 2A-C). The human foreskin fibroblast (HFF) used as control demonstrated similar growth kinetics as monoculture upon both contact and paracrine co-culture with lipoaspirate (Figure 2D). We further confirmed our contact co-culture cell count results by fluorescent-based DNA measurement (Figure S1A,B). In addition, no enhancement in MCF-7 or MDA-MB-231 proliferation rate was observed upon co-culture with lipoaspirates obtained from cancer patients (Figure S1C,D). Titrating the proliferation pattern of MCF-7 in contact co-culture with lipoaspirates showed the largest drop in proliferation at day 3 post co-culture (Figure S1E). Microscopic images revealed a stressed morphology in the contact cultured MCF-7 and MDA-MB 231 cells (Figure 2E,F). We confirmed the viability of the lipoaspirates at the end of the co-culture experiments by isolating and culturing the adipose-derived stem cells following digestion of lipoaspirates with collagenase enzyme. Isolated ASCs demonstrated comparable morphology and growth kinetics to freshly isolated ASCs (data not shown). These results indicate that lipoaspirates do not promote the proliferation of breast cancer cells, rather suggesting that a contact-dependent proliferation inhibition is the most likely outcome.

\subsection{Conditioned Mediums from Lipoaspirate Co-Culture Do Not Promote the Proliferation of Breast Cancer Cells in Culture}

We collected the cell culture supernatant from mono-cultured, contact-cultured and paracrine-cultured breast cancer cells lines with lipoaspirates. After filtration, we used this conditioned media to culture breast cancer cell lines. The cell counts after 5 days of culture indicated that conditioned media from both contact- and paracrine-co-cultured MCF-7 and lipoaspirates inhibited the proliferation of MCF-7 compared to cells cultured in supernatant from monoculture (Figure 3A). No change in the proliferation rates of MDA-MB-231 and BT-474 cells was observed in different conditioned mediums (Figure 3B,C, respectively). These results indicated that factors released by lipoaspirates selectively inhibit MCF-7 cells proliferation and lipoaspirate-conditioned medium does not promote breast cancer cells proliferation.

\subsection{ASCs Contact Culture Inhibit the Proliferation of MDA-MB-231 Cells}

Previous studies have reported conflicting results regarding the role of ASCs in promoting the proliferation and malignant transformation of breast cancer cells [2,14-16,22,25]. We isolated ASCs from the same donors from whom lipoaspirates were obtained and propagated them in vitro. Transwell co-cultures were performed by seeding breast cancer cells MCF-7, MDA-MB231 or BT-474 on the lower plastic surface, and ASCs were seeded in the transwell basket. Cell count analyses of breast cancer cells 5 days post co-culture revealed no differences in the growth kinetics of co-cultured breast cancer cells compared to mono-cultured cells (Figure 3D-F). EMT plays an important role in breast cancer metastasis. We analyzed the effects of the ASCs co-culture on the expression of EMT-related genes in breast cancer cell lines. Quantitative real-time PCR analyses of EMT genes TWIST1, Snail1, Snail2 and $\mathrm{CDH} 2$ in monocultured and ASCs co-cultured MCF-7 (Figure 3G) and MDA-MB-231 (Figure 3H) revealed that most of these EMT signature genes were downregulated in co-cultured breast cancer cells.

Since our lipoaspirates contact co-culture studies showed inhibitory effects on the proliferation of MCF-7 cells, we planned a contact co-culture of ASCs with breast cancer cells MCF-7 and MDA-MB-231. GFP-expressing MCF-7 and MDA-MB-231 cell lines were generated and sorted (Figure S2A,B). ASCs were grown to full confluency and also mixed with the monocultured GFP-expressing breast cancer cells as shown in (Figure S2C) to achieve a consistency in downstream analyses. A FACS event count for $60 \mathrm{~s}$ at a constant flow rate revealed a significantly lower green events count upon the co-culturing of ASCs with GFP-MDA-MB-231 cells (Figure 4A-C). No significant differences were observed in the events count of monocultured and co-cultured GFP-MCF-7 cells (Figure 4D-F). The FACS count results were further confirmed by manually counting the total number of the cells (Figure $4 \mathrm{G}, \mathrm{H}$ ) and by the visualization of green cells using fluorescent microscopy (Figure $4 \mathrm{I}, \mathrm{J}$ ). 
We conclude that neither the paracrine nor the contact co-culture of ASCs promote the proliferation of ASCs; rather, a direct cell-cell contact of ASCs with MDA-MB-231 cells reduces the MDA-MB-231 cells' proliferation rate.

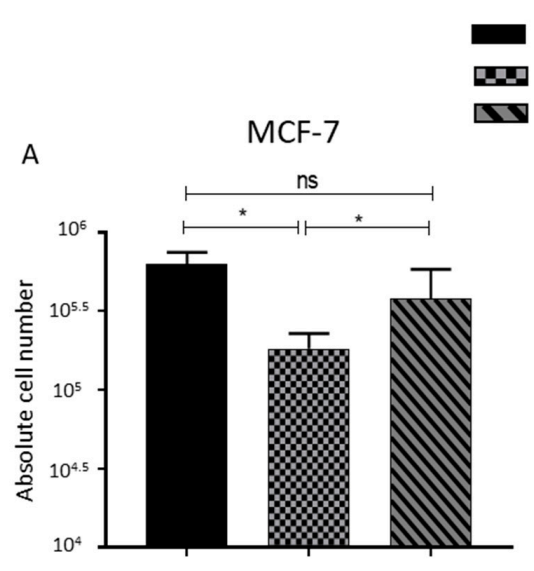

BT-474

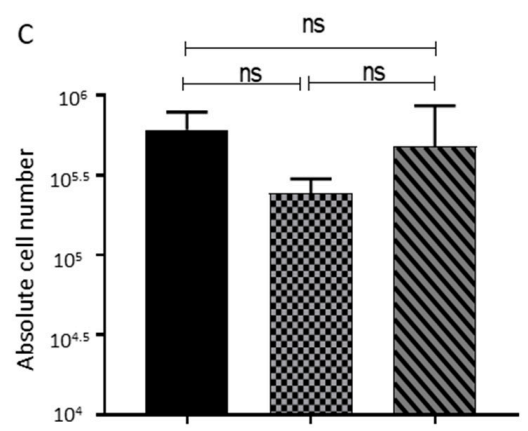

Monoculture Contact co-culture

Paracrine co-culture

B

MDA-MB-231

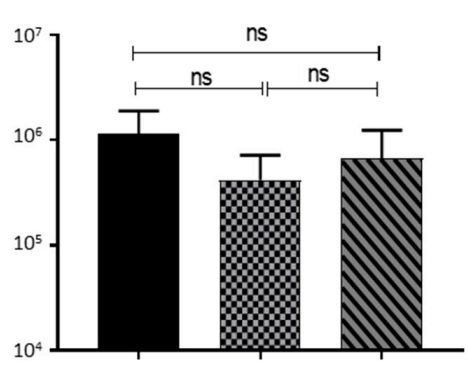

HFF

D

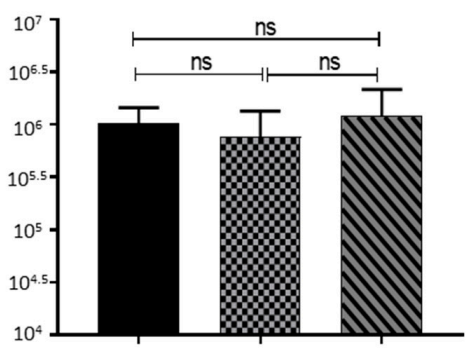

$$
E
$$
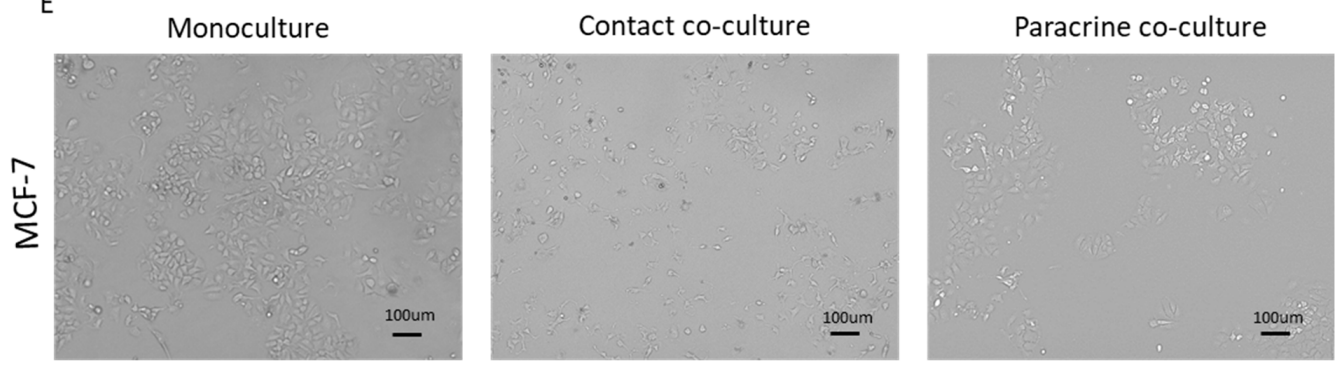

F
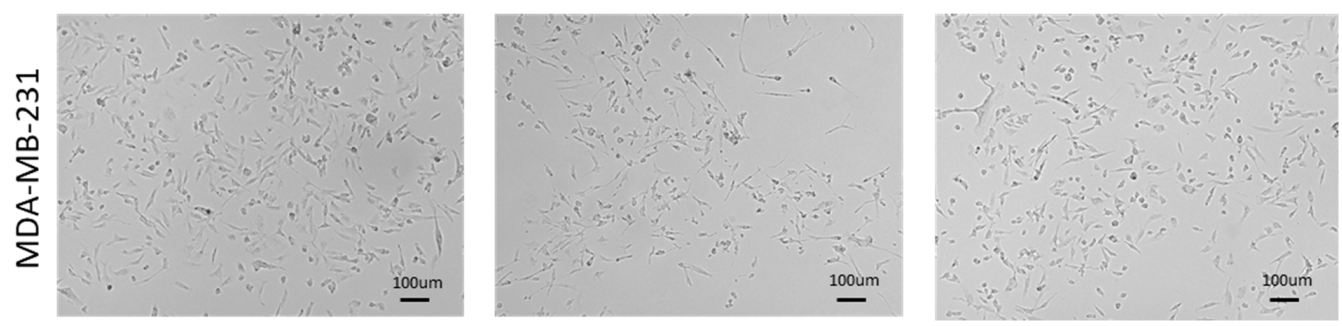

Figure 2. Contact and paracrine co-culture of lipoaspirate do not promote breast cancer cells' proliferation. (A-D) Absolute cell count obtained using Neubauer counting chamber after 4 days of either contact or paracrine co-culture of lipoaspirates with MCF-7 (A), MDA-MB-231 (B), BT-474 (C), or human foreskin fibroblast (HFF) (D). Graphs are representative of the results obtained using lipoaspirate from 3 different donors. $p$ value $<0.05={ }^{*}$, ns $=$ non-significant. (E,F) Bright field microscope images of contact and paracrine co-culture of MCF-7 and MDA-MB-231 cells with lipoaspirates. 

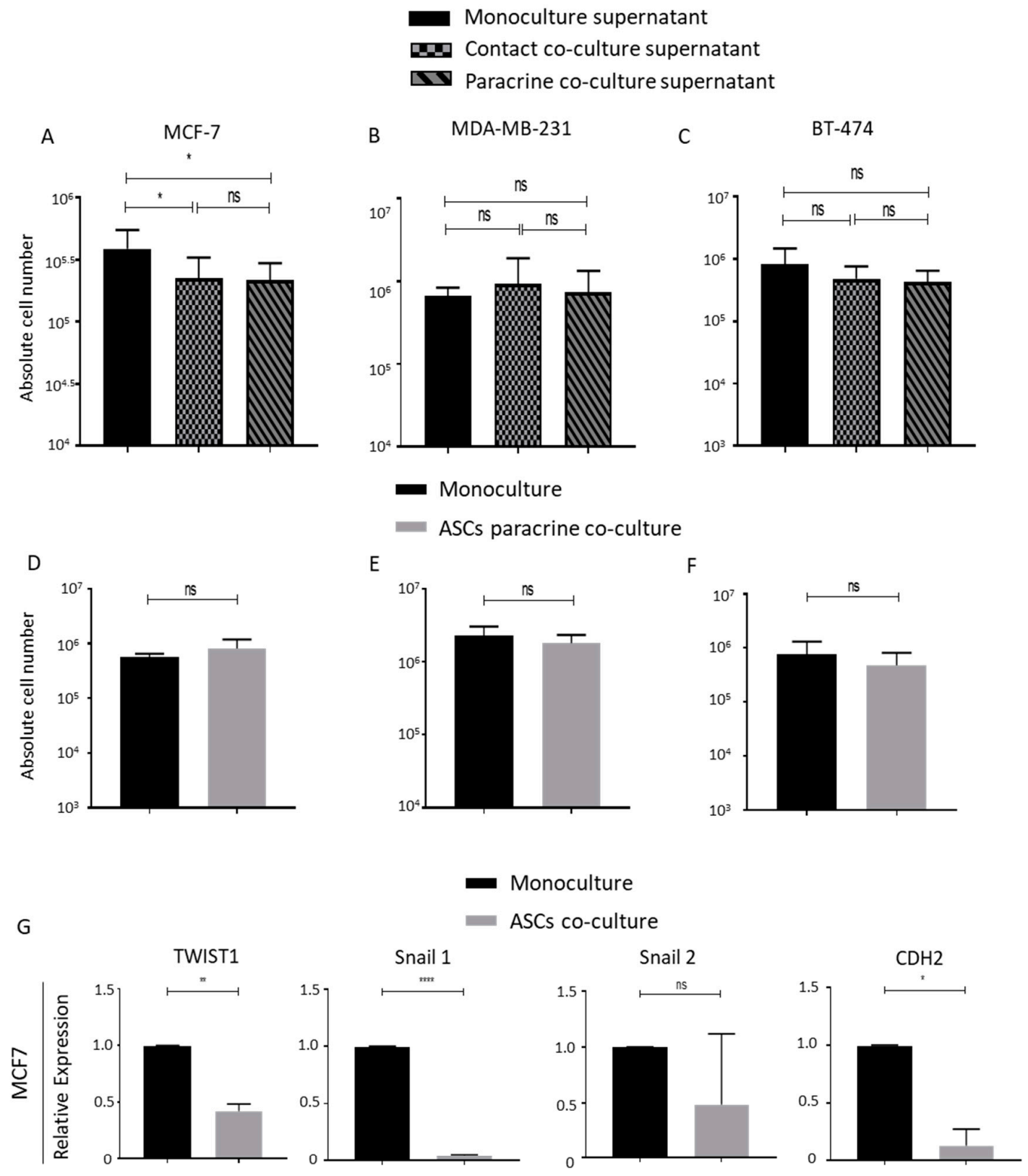

$\mathrm{H}$
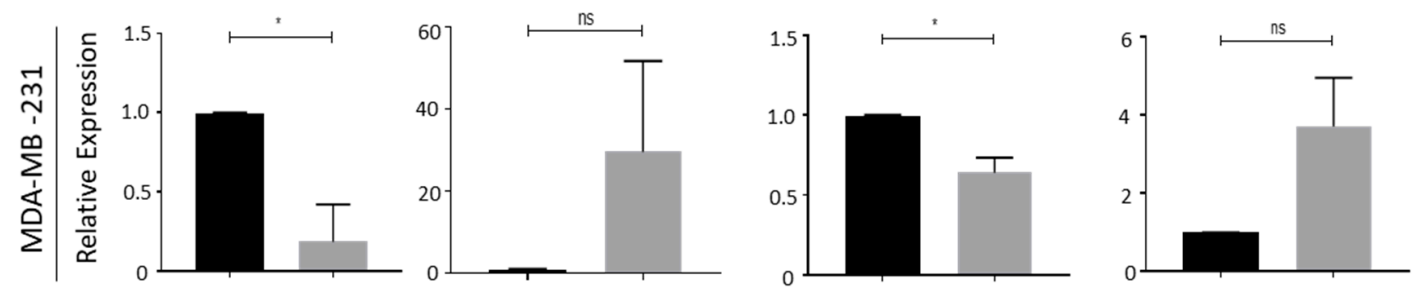

Figure 3. Transwell paracrine culture of ASCs does not promote breast cancer cells proliferation. (A-C) Absolute cell count obtained using Neubauer counting chamber after 4 days of culture of either MCF-7 (A), MDA-MB-231 (B) or BT-474 (C), in cell culture supernatant collected from either monocultured, contact-co-cultured or paracrine-cultured breast cancer cells with lipoaspirates. Graphs are representative of 3 independent experiments. (D-F) Representative graph of cell count of MCF-7 (D), MDA-MB-231 (E) and BT-474 (F) cell upon transwell co-culture with ASCs. ASCs from 3 different donors were employed. (G,H) Relative EMT genes expression of monocultured or co-cultured MCF-7 (G) and MDA-MB-231 (H) was analyzed by quantitative real-time PCR. $p$ value $<0.05={ }^{*}, p<0.01={ }^{* *}$, $p<0.0001=^{* * * *}, \mathrm{~ns}=$ non-significant. 


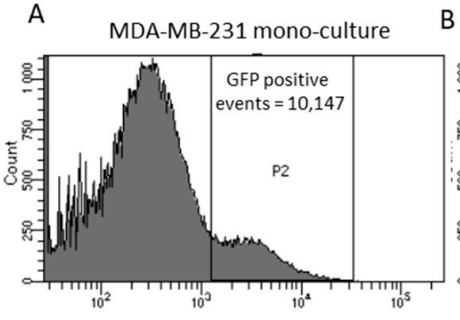

GFP

B

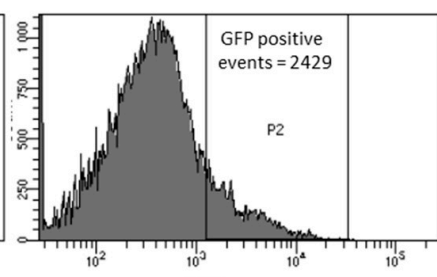

GFP

E

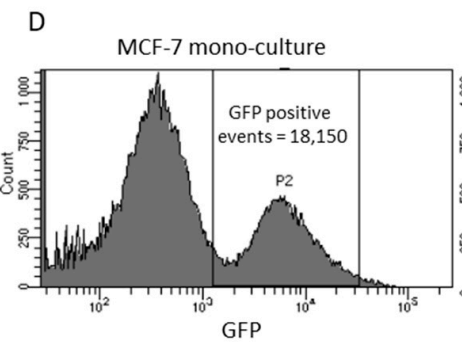

D

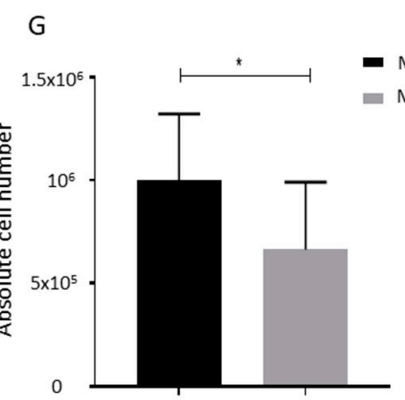

I

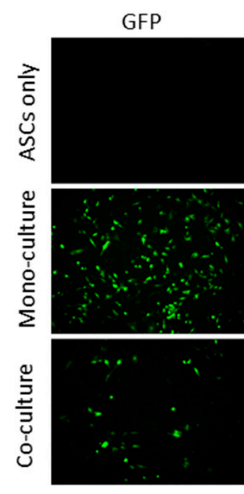

MDA-MB-231

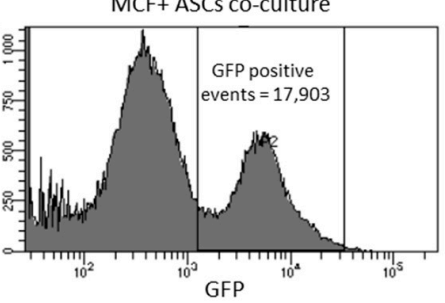

$\mathrm{H}$

J

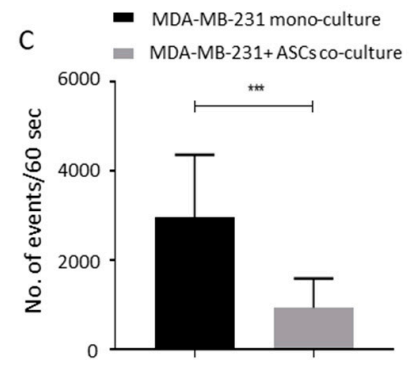

F

- MCF-7 mono-culture - MCF-7+ASCs co-culture

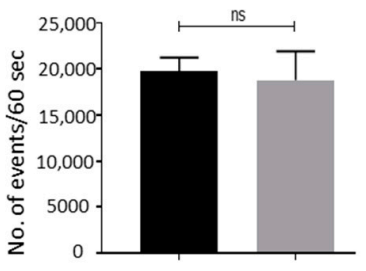

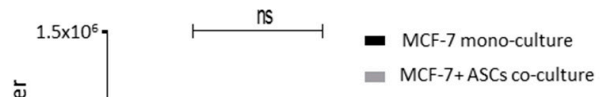
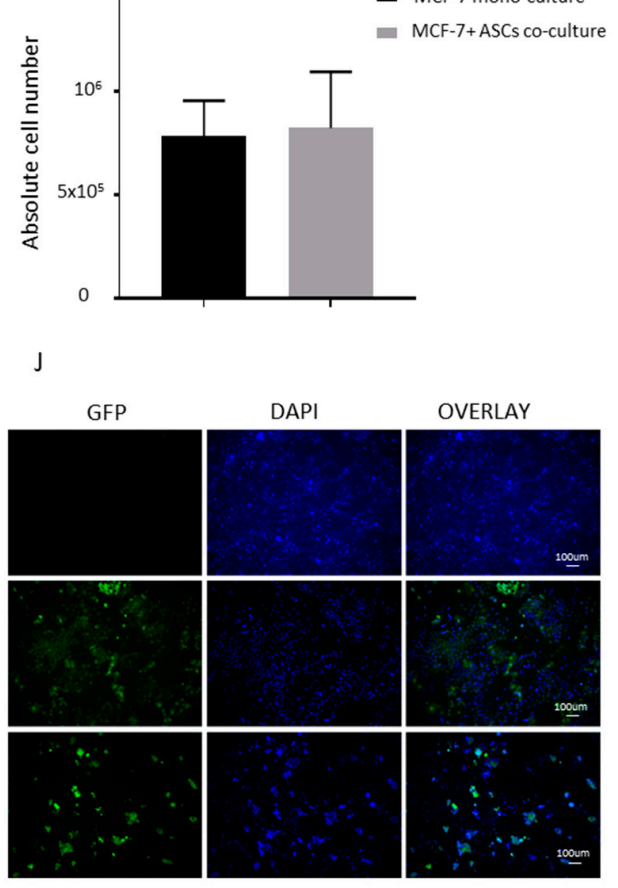

MCF-7

Figure 4. ASCs contact culture inhibits the proliferation of MDA-MB-231 cells. (A-C) Contact co-culture of MDA-MB-231 cells with ASCs. MDA-MB-231 expressing GFP were seeded either alone (A) or on confluent ASCs (B) for 4 days. The numbers of GFP-positive events per minute were counted 4 days post culture by using flow cytometry and plotted (C). (D-F) Contact co-culture of MCF-7 cells with ASCs. MCF-7 cells expressing GFP were seeded either alone (D) or on confluent ASCs (E) for 4 days. The numbers of GFP positive events per minute were counted 4 days post culture by using flow cytometry, and plotted (F). The graphs are representative of 3 independent experiments using ASCs from different donors. $(\mathbf{G}, \mathbf{H})$ Absolute number of cells counted by Neubauer chamber from the experimental settings $(\mathbf{A}, \mathbf{B})$ shown in $(\mathbf{G})$ and from $(\mathbf{D}, \mathbf{E})$ as reflected in $(\mathbf{H})$. (I,J) Fluorescent microscope images of MDA-MB-231/ASCs co-culture (I) and MCF-7/ASCs co-culture (J) are shown. GFP-positive cells are green while nuclear stain DAPI stain blue. $p$ value $<0.05={ }^{*}, p<0.001={ }^{* * *}$, ns = non-significant. 


\subsection{Lipoaspirate Contact Co-Culture Inhibit Cell Cycle in MCF-7 Cells}

To understand the possible underlying mechanism involved in the lipoaspirate contact co-culture-mediated reduction in MCF-7 proliferation, we first analyzed a possible induction of apoptotic cell death in co-cultured breast cancer cells. Annexin/PI staining of co-cultured cells showed no notable changes in annexin/PI-positive cell percentages (Figure 5A).

A

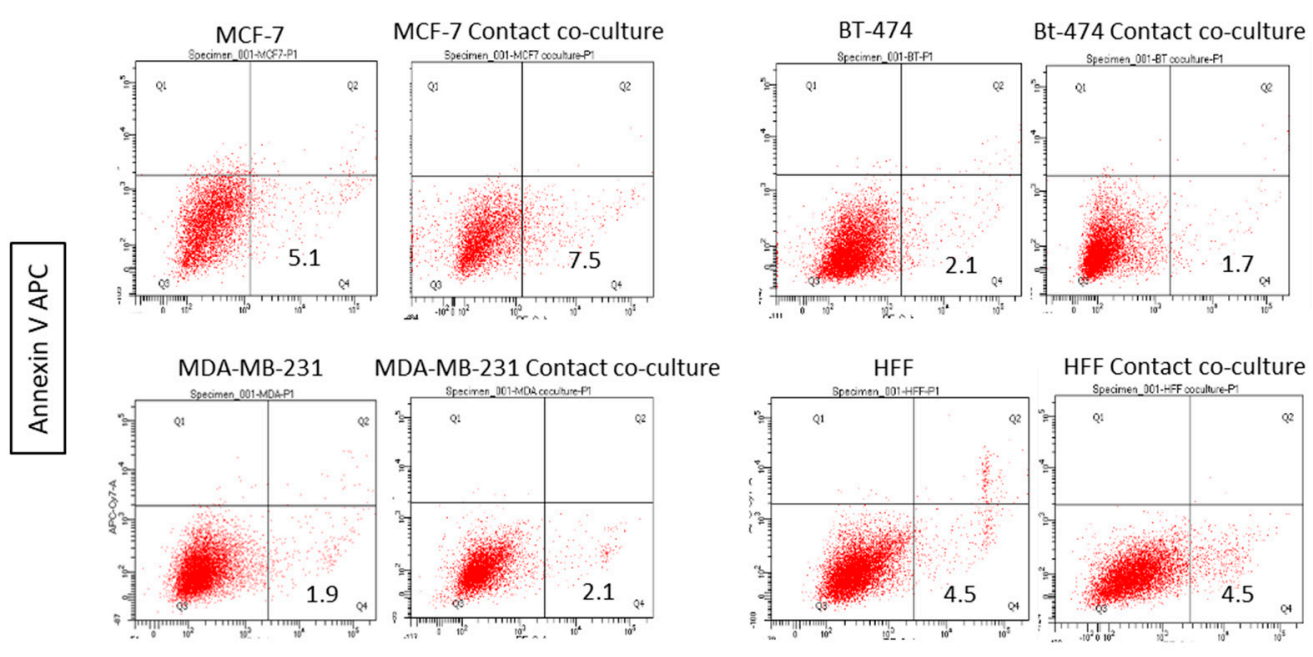

Propidium iodide

B
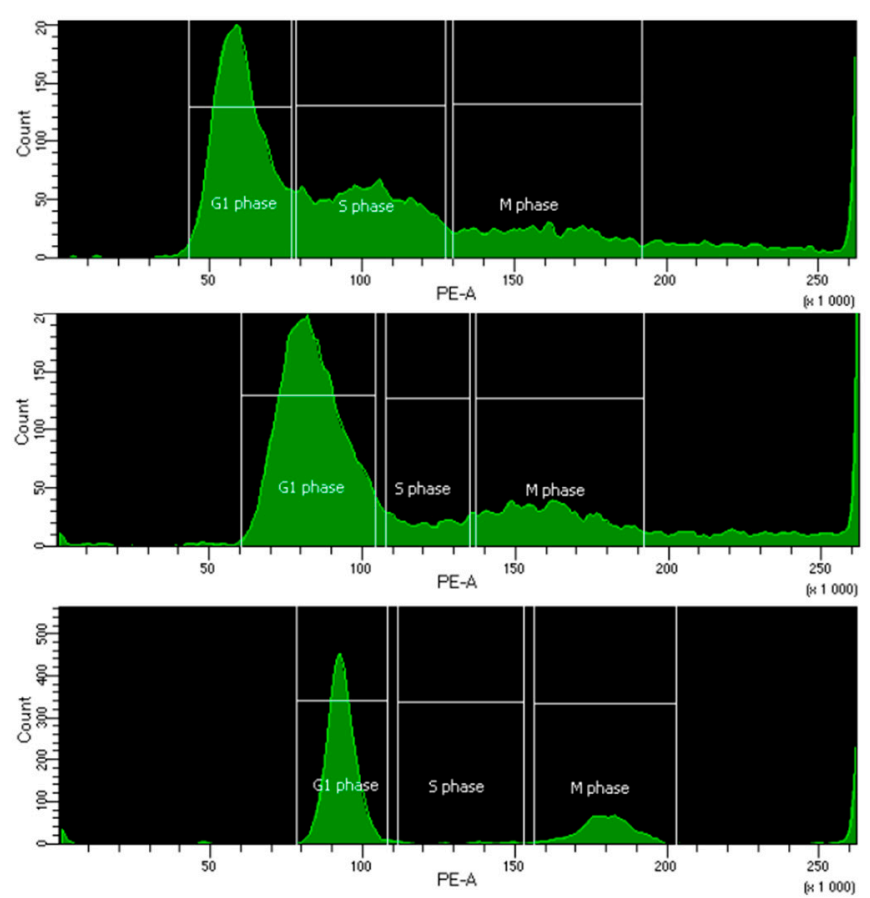

Monoculture

Contact co-culture

$\square$ Paracrine co-culture
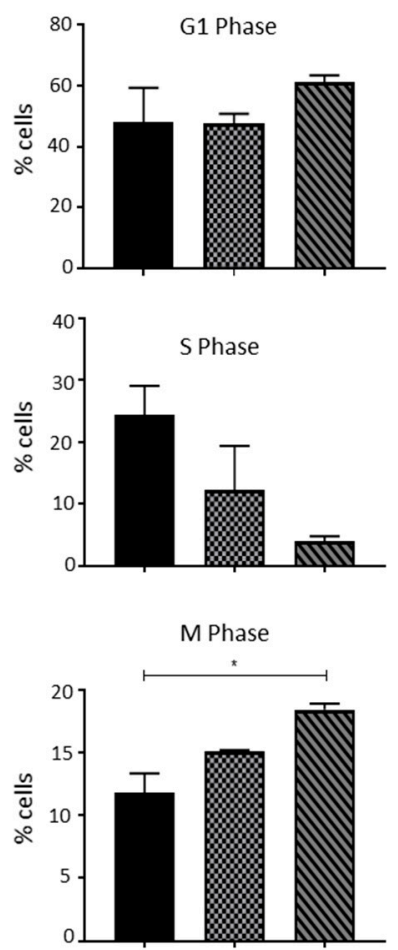

Figure 5. Lipoaspirate contact culture results in cell cycle arrest in MCF-7 cells. (A) Effect of lipo-aspirate contact co-culture on breast cancer cell survival. AnnexinV/Propidium Iodide staining was employed to estimate the cell death of breast cancer cells upon co-culture. (B) Cell cycle analyses of paracrine and contact-co-cultured MCF-7 cells with lipo-aspirates. Graphs show the percentages of cells in different phases of cells upon different culture conditions. $p$ value $<0.05=*$. 
Next, we analyzed the distributions of cells in different phases of the cell cycle by trypsanizing and staining the fixed cells with propidium iodide. FACS analyses of the DNA content revealed that upon the contact co-culture of MCF-7 cells with lipoaspirates, the majority of MCF-7 cells were arrested in either the G1 or M phase, and a very small percentage of the cells were in the $S$ phase as compared to the monocultured cells (Figure 5B, left and right panel). The paracrine co-cultured cells showed a comparable distribution of cells to monocultured cells. Of note, paracrine- and contact-co-cultured MDA-MB-231 cells showed no differences in the distribution of the cells in different phases of the cell cycle compared to monocultured cells (data not shown).

\subsection{Lipoaspirate Contact Co-Culture and Supernatant Activate Retinoblastoma Protein (RB) Mediated Cell Cycle Arrest in MCF-7 Cells}

Mitogenic stimulation results in cyclin-dependent, kinase-mediated phosphorylation of the RB protein, thus inhibiting their growth inhibitory functions and allowing the cells to enter the $S$ phase of the cell cycle [26]. We analyzed the expression of cell cycle regulators in MCF-7 and MDA-MB-231 cells contact-co-cultured with lipoaspirates. Consistent with the lower proliferation rate and cell cycle arrest observed in co-cultured MCF-7 cells, we observed a significant decrease in the phosphorylation of RB protein, reflecting enhanced cell cycle inhibitory function of RB protein (Figure 6A, left and right panel). No significant effect on RB phosphorylation was observed in lipoaspirate contact-co-cultured MDA-MB-231 or control HFF cells (Figure 6A, left and right panel). We observed a decrease in the expression of the tumor suppressor p53 but no changes in p21 protein levels in MCF-7 and MDA-MB-231 cells, indicating a possible compensatory regulation of p53 expression (Figure 6A, left and right panel). To confirm the possible role of RB protein activity in the reduced proliferation of co-cultured MCF-7 cells, we cultured MCF-7 cells in the supernatant collected from the lipoaspirate paracrine and contact culture experiment. Western blot analyses of these MCF-7 cells revealed that the supernatant from contact culture experiments inhibits RB protein phosphorylation (Figure 6B, left and right panel). The inhibition of RB protein phosphorylation in MCF7 cells using CDK 4/6 inhibitor PD0332991 resulted in reduced proliferation (Figure 6C,D). We conclude that lipoaspirate contact culture inhibits MCF-7 proliferation via RB protein. 
A
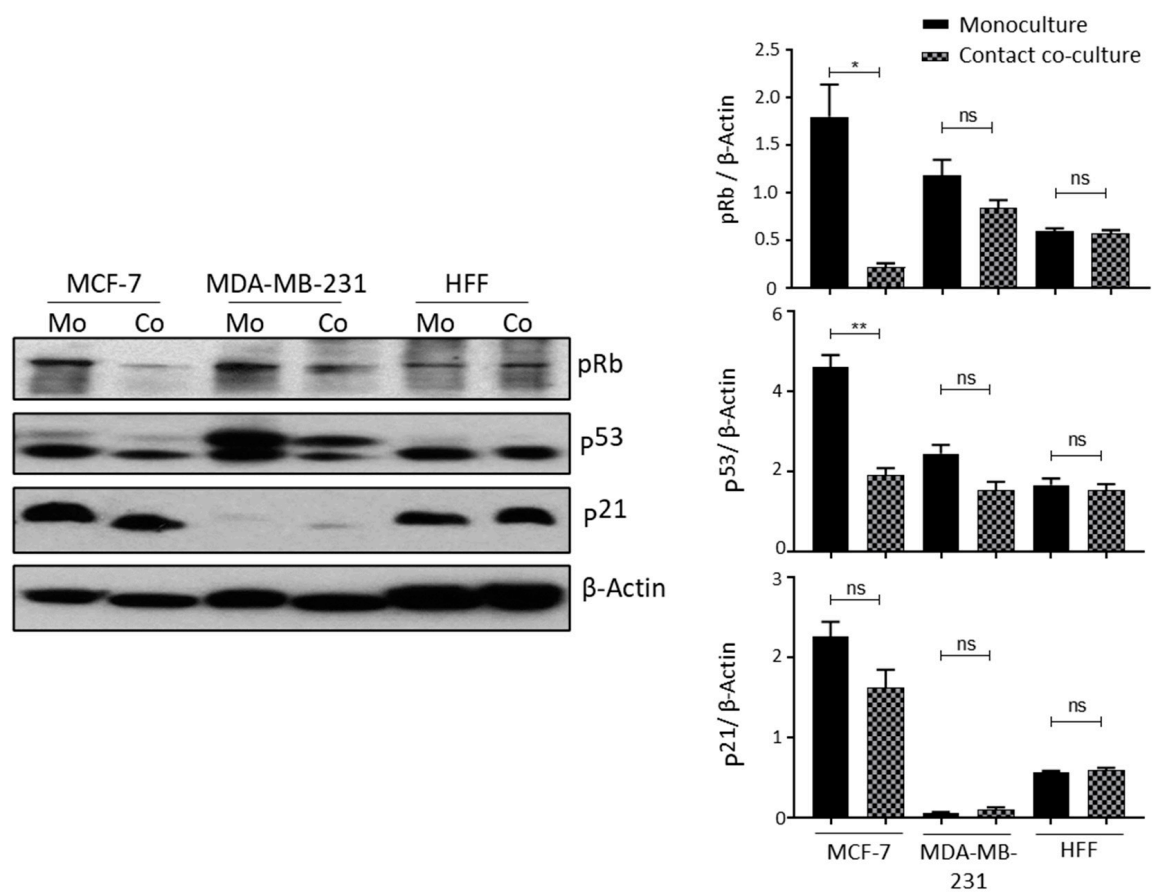

B

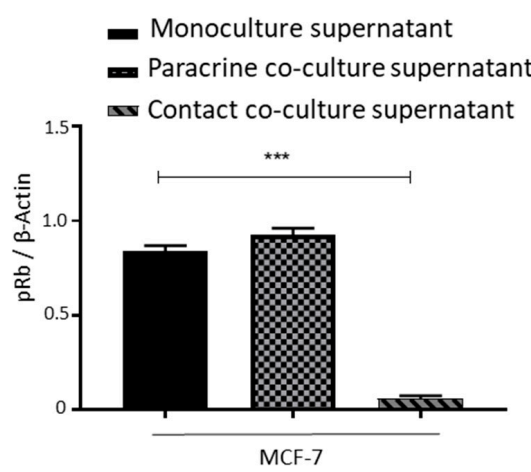

C

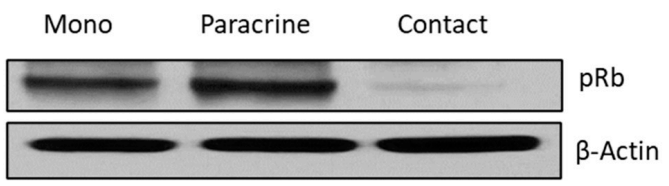

Control PD0332991
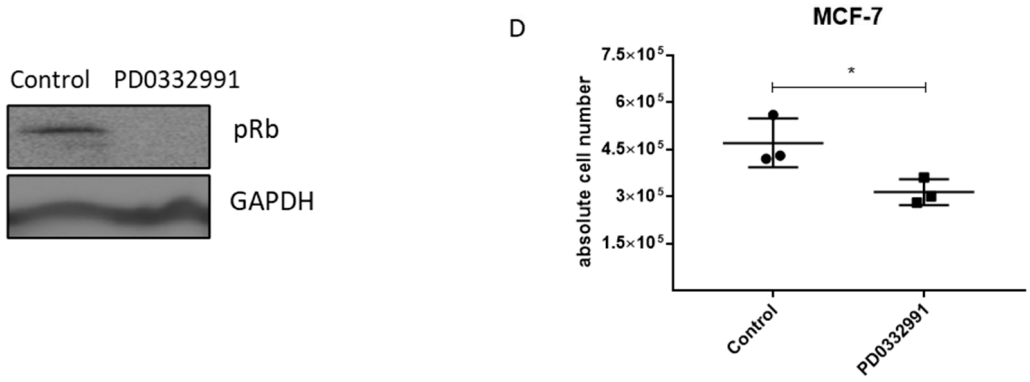

Figure 6. Contact lipoaspirate culture inhibits MCF-7 proliferation via the retinoblastoma-mediated pathway. (A) Cell lysates from MCF-7, MDA-MB-231 or HFF contact-co-cultured with lipo-aspirates were collected in Ripa lysate buffer. The phosphorylation of retinoblastoma protein $(\mathrm{Rb})$ and the expression of p53 and p21 were analyzed by western blotting using specific antibodies. $\beta$-Actin was employed as the loading control. Fold changes in densitometric band intensities, acquired by image J and normalized to $\beta$-Actin, were compared and plotted. (B) Cell lysates from MCF-7 cells cultured in media from either monocultured, paracrine-cultured or contact-cultured MCF-cells with lipo-aspirates were collected in Ripa buffer and blotted for phosphorylated retinoblastoma protein (Rb). $\beta$-Actin was

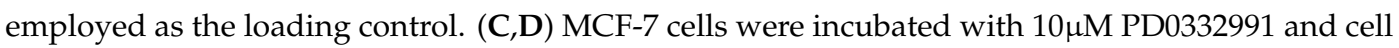
lysates were blotted for $\mathrm{Rb}$ protein phosphorylation $(\mathrm{C})$ and counted at day 4 post seeding (D). $p$ value $<0.05={ }^{*}, p<0.01={ }^{* *}, p<0.001=^{* * *}$, ns $=$ non-significant. 


\section{Discussion}

AFT has been widely adapted for breast reconstruction procedures given its autologous nature and regenerative properties. However, the oncological safety of AFT has been hotly debated, with opposing basic science and clinical literature findings that have polarized plastic surgeons' and oncologists' opinions on the cost-benefit tradeoffs of AFT. Despite the large number of studies surrounding the topic, the field still lacks a clear direction due to conflicting reports from the variable choices of in vitro and in vivo study models. For example, in vitro studies utilized ASCs, in vitro differentiated adipocytes or floating adipocytes as the co-culture interaction partner of breast cancer cells, and reported the tumorigenic behavior of the breast cancer cells $[14,16,20,22]$. These interactive studies may not reflect the actual clinical scenario of AFT, where lipoaspirates are injected into tumor beds that may or may not have remnant active tumor cells. Lipoaspirates represent a smaller unit of fat tissue that still comprise a cellular milieu, including adipocytes, ASCs, preadipocytes, pericytes, endothelial cells and hematopoietic lineage cells [27]. The in vitro propagation of cells outside their natural microenvironment alters their behavior. Gebremeskel et al. showed the higher expression of tumorigenic genes, such as Arg-1, TGF- $\beta$ and VEGF, in cultured ASCs as compared to fat graft [28]. Thus, in vitro studies involving ASCs, in vitro-differentiated adipocytes or floating adipocytes may not be the true reflection of the interaction of these cells with breast cancer cells in a clinical setting. To overcome these possible technical shortcomings and simulate a more accurate clinical scenario, we carried out a cell-cell contact and a paracrine interaction study between fresh lipoaspirates and breast cancer cell lines. To our knowledge, this is the first attempt to study the contact-dependent interaction between lipoaspirates and breast cancer cells. We performed these studies in a closed flask culture system to prevent the exposure of the floating lipoaspirates to the air interface during the culture, which can result in possible cell death and the release of pro-inflammatory cytokines into the culture medium.

Employing our lipoaspirate co-culture system, we observed a significant decrease in the proliferation rate of MCF-7 cells in both the paracrine and contact co-culture settings. The other tested breast cancer cell lines MDA-MB-231 and BT-474 showed no difference in the proliferation pattern compared to the mono-cultured cells. Similarly, our control cell line HFF showed no notable effect of co-culturing with lipoaspirates on proliferation. These results indicate that lipoaspirate selectively inhibits MCF-7 cells' proliferation in vitro, and likely has no impact on normal healthy cells. We have previously shown that lipofilling following MCF-7 cells engraftment resulted in significantly lower tumor volume and mass, and showed significantly lower Ki-67 proliferation index [23]. A separate study showed that free fatty acids released by subcutaneous fat inhibit the proliferation of MCF-7 as a possible mechanism [29]. In line with our in vitro results showing no changes in MDA-MB-231 cells' proliferation pattern in co-culture, fat grafting studies in mice showed no significant changes in the MDA-MB-231 tumor volume [22,25]. On the other hand, two independent studies using a transwell paracrine co-culture system showed an increase in the MCF-7 cells' proliferation upon incubation with lipoaspirate [20,21]. One possibility for this contrary observation could be the potential interference resulting from the damage induced by the exposure of the lipoaspirate to the air interface, which results in rapid phenotype loss due to hypoxia and inflammation [30,31]. Noting this potential problem with adipocyte culture, a recent study has shown an 'under membrane' transwell alternative culture technique, which maintains the identity and function of adipocytes. This technique can be used as a potential technical resource for performing paracrine interaction studies [32]. Using our flask culture, we also avoided the potential interference of hypoxia-induced inflammation in our culture conditions. In addition, the supernatant from the lipoaspirate co-culture showed an inhibitory effect on the proliferation of MCF-7 cells.

Our result from the paracrine transwell co-culture of ASCs with breast cancer cells demonstrated no significant change in the proliferation of MCF-7, MDA-MB-231 or BT-474 cells. In these studies, we used ASCs isolated from the same lipoaspirates donors to comprehensively compare the effects of different cell processing techniques, from the same source, on tumorigenic outcomes. Although ASCs 
alone are not currently employed as a tool for reconstruction procedures, they constitute a major fraction of the adipose tissue stromal vesicular fraction (SVF). Moreover, in some AFT protocols, SVF-enriched lipoaspirates are used to enhance the graft volume retention [33]. One clinical study found no significant difference in cancer recurrence in patients who received SVF-enriched lipoaspirates for breast reconstruction as compared to the control group [33]. Similarly, co-culture with ASCs showed no significant effect on the proliferation of MCF-7 or MDA-MB-231 cells [2]. Contrarily, Ritter et al. reported an increase in the proliferation of the MCF-7 cells upon co-culture with ASCs [34]. A possible explanation for these differing observations could be the use of different ASCs ratios in the co-culture experiments. We used a 1:6 MCF-7 to ASCs ratio in our co-culture experiment compared to the 5:1 ratio used by Ritter et al. The choice of the 1:6 MCF-7 to ASCs ratio in our study was made considering the clinical scenario of AFT, which is performed after confirmation of no active cancer. Therefore, very few remnant cancer cells are expected, even if some survive radio- and chemotherapy. Supporting this reasoning, Ryu et al. have shown that high-density cultured ASCs even suppress the growth of MCF-7 cells [35]. Our cell-cell contact culture also showed no increase in the proliferation of MCF-7 cells. Intriguingly, we instead observed a significant decrease in the proliferation rate of MDA-MB-231 cells. Previous studies reported a similar inhibitory effect of ASCs contact culture on the proliferation of MDA-MB-231 cells, most likely through a (TNF)- $\alpha$-related apoptosis-inducing ligand (TRAIL)-mediated interaction $[34,36]$. Finally, our results showed retinoblastoma protein mediated cell cycle arrest as a possible mechanism involved in the lipoaspirate co-culture-dependent inhibition of MCF-7 cells proliferation. Interestingly, we observed a downregulation of p53 protein expression in MCF-7 cells, which most likely is a compensatory mechanism to balance Rb protein activity [37].

\section{Materials and Methods}

\subsection{Donor Specification}

Adipose tissue was collected from 5 female donors in the age range $39 \pm 13$ and BMI range $27 \pm 4$ undergoing elective plastic surgery procedures at the University of Pittsburgh Medical Center (UPMC). The procedure of tissue collection was approved by the University of Pittsburgh Institutional Review Board (IRB No. 0511186). Fat tissue aspirates were collected in $20 \mathrm{~mL}$ syringes and centrifuged at $3000 \mathrm{rpm}$ for $5 \mathrm{~min}$. The upper oil layer and lower aqueous layer were discarded, and the middle layer was washed with PBS and used in co-culture experiments.

\subsection{Isolation of Human Adipose-Derived Stem Cells}

Human subcutaneous white adipose tissue (sWAT) samples were harvested from donors undergoing routine abdominoplasty at the Department of Plastic Surgery, University of Pittsburgh. The tissue collection methods were approved by the Institutional Review Board (IRB No. 0511186). All sWAT samples were obtained from the lower abdomen. Adipose tissue biopsies after surgery procedures were transferred to the lab in sterile containers before processing in a laminar flow sterile work bench class II. Tissue was rinsed 3 times with PBS (Sigma, St. Louis, MO, USA), followed by the removal of fibrous material and blood vessels by dissection.

The tissue was cut into pieces ( 1-2 mg) and digested in digestion buffer (PBS) containing 200 U/mL collagenase (CLS Type II, Worthington Biochemical Corp., Lakewood, NJ, USA) and 2\% $w / v$ BSA (Sigma, St. Louis, MO, USA) under stirring for $60 \mathrm{~min}$ at $37^{\circ} \mathrm{C}$ and $450 \mathrm{rpm} ; 1 \mathrm{~g}$ adipose tissue $/ 3 \mathrm{~mL}$ digestion buffer. The dispersed tissue was centrifuged for $10 \mathrm{~min}$ at $200 \mathrm{RCF}$ at room temperature. The floating adipocytes were aspirated, and the sedimented stromal-vascular fraction (SVF) was suspended in erythrocyte lysis buffer (0.155 M NH4CI, 5.7 mM K2HPO4, 0.1 mM EDTA, $\mathrm{pH}$ 7.3) and incubated for $10 \mathrm{~min}$ at room temperature.

To remove tissue debris, the cell suspension was filtered through a nylon mesh (pore size $100 \mu \mathrm{m}$, BD, USA). After another centrifugation step (10 min at $200 \mathrm{RCF}$ ), the pelleted SVF was suspended in DMEM/F12 medium (Sigma, St. Louis, MO, USA), supplemented with 10\% FBS (Sigma, St. Louis, 
MO, USA), and filtered through a $40 \mu \mathrm{m}$ mesh to remove residual cell aggregates. SVF cells were inoculated into cell culture flasks at a density of $30,000 / \mathrm{cm}^{2}$. The attached cell population at one-week post-culture was referred to as the adipose-derived stromal cell (ASC) fraction and used for further studies. The ASC cell population contained an enriched population of adipose stem/progenitor cells.

\subsection{Culture of ASCS}

Upon reaching 70\% confluence in the T175 flask (Thermo Fisher Scientific, Waltham, MA, USA), the ASCs were washed with phosphate buffered saline (PBS, Thermo Fisher Scientific, Waltham, MA, USA) and trypsinized using $3 \mathrm{~mL}$ 0.5\% trypsin-EDTA 1x (Sigma, St. Louis, MO, USA). Trypsin was neutralized using $7 \mathrm{~mL}$ DMEM/F12 medium, 10\% FBS medium and $50 \mu \mathrm{g} / \mathrm{mL}$ Gentamicin (Invitrogen, Carlsbad, CA, USA), and removed by centrifugation at $300 \mathrm{RCF}$ for $5 \mathrm{~min}$. The cells were again seeded at a density of $5000-7000 \mathrm{cells} / \mathrm{cm}^{2}$ in DMEM/F12 medium plus $10 \% \mathrm{FBS}$, and maintained at $37^{\circ} \mathrm{C}$ with $5 \% \mathrm{CO}_{2}$. ASCs were passaged by seeding at $5000-7000 \mathrm{cells} / \mathrm{cm}^{2}$, the medium was changed every third day and the cells were grown to $70 \%$ confluence before splitting. ASCs cultivated to passage 3-4 were used in this study.

\subsection{Culture of Breast Cancer Cell lines}

BT-474, MDA-MB-231 and MCF-7 cell lines were purchased from American Type Culture Collection (ATCC, Manassas, VA, USA), and cultured in DMEM medium (Sigma, St. Louis, MO, USA) supplemented with $10 \% \mathrm{FCS}$ and antibiotics. Cells were cultured at $37^{\circ} \mathrm{C}$ and $5 \% \mathrm{CO}_{2}$.

\subsection{Culture of Human Foreskin Fibroblasts (HFF)}

Human foreskin fibroblasts were obtained from ATCC and cultivated using methods described by Cavinato et al. [38]. Briefly, 5000 cells $/ \mathrm{cm}^{2}$ were seeded in T25 flask in DMEM (Sigma, St. Louis, MO, USA) medium supplemented with $10 \%$ FCS.

\subsection{Inverted Flask Culture: Contact Co-Culture}

MCF-7, MDA-MB 231, BT-474 or HFF $1 \times 10^{5}$ cells were seeded in vented T12.5 flasks (Corning, $\mathrm{NY}, \mathrm{USA}$ ) in $3 \mathrm{~mL} \mathrm{DMEM}, 10 \% \mathrm{FCS}$ medium and cultured overnight at $37^{\circ} \mathrm{C}$ and $5 \% \mathrm{CO}_{2}$. After $24 \mathrm{~h}$, $1 \mathrm{~mL}$ lipoaspirate was added in the flask and the flasks were filled completely with medium. Following lipoaspirate addition, the flasks were cultured with the bottom side seeded with cultured breast cancer cells. The flasks were inverted such that the cells faced down, as shown in Figure 1D. Since lipoaspirate is buoyant and tends to float on the surface of the medium, this arrangement allowed the lipoaspirate to float to the top of the inverted flask, thus maintaining contact with the seeded breast cancer cells. Co-cultures were performed for 4 days without performing any media change unless indicated, and the proliferation outcome was recorded by either cell count using Neubauer chamber or fluorescent DNA quantification-based assay Cy-QUANT (Thermo Fisher Scientific, Waltham, MA, USA).

\subsection{Conventional Flask Culture: Paracrine Co-Culture}

MCF-7, MDA-MB 231, BT-474 or HFF $1 \times 10^{5}$ cells were seeded in T12.5 flasks (Corning, NY, USA) in $3 \mathrm{~mL} \mathrm{DMEM,} 10 \% \mathrm{FCS}$ medium and cultured overnight at $37{ }^{\circ} \mathrm{C}$ and $5 \% \mathrm{CO}_{2}$. After $24 \mathrm{~h}$, $1 \mathrm{~mL}$ lipoaspirate was added in the flask and flasks were filled completely with medium. Flasks were cultured in conventional culture position as shown in Figure 1C. This arrangement allowed the lipoaspirate to float to the top and created a paracrine co-culture environment where both cancer cells and lipoaspirates were cultured in the same flask without being in contact. Following 4 days of co-culture, the cells were counted using a Neubauer chamber. 


\subsection{Transwell Co-Culture Experiments}

A Transwell system (0.4 $\mu$ m pore size, Polyester (PET) membrane; Corning, Corning, NY, USA) was employed. Either $5 \times 10^{4}$ MCF-7 or MDA-MB231 or BT-474 were cultured in the bottom surface of a 6-well plate. $3 \times 10^{5}$ Human ASCs were cultured in the upper transwell basket. The co-culture was performed for 5 days followed by a cell count using a Neubauer chamber. Wells without ASCs in the transwell were counted as control and compared with co-cultured cell counts.

\subsection{Generation of GFP-Expressing Breast Cancer Cell Lines}

GFP-expressing MCF-7 and MDA-MB-231 cell lines were generated by transfecting the cells with p-Lenti-CMV-MCS-GFP-SV-puro plasmid (addgene Plasmid \# 73582). Cells were grown to 70\% confluency in 6-well plates and transfected with 2ug plasmid DNA using lipofectamine 2000 (Thermo Fisher Scientific, Waltham, MA, USA) following manufacturer's protocol. After $48 \mathrm{~h}$ of transfection, cells were selected with puromycin for 1 week. GFP-positive cells were sorted by FACS and used in co-culture experiments (Figure S2A,B).

\subsection{ASCs Breast Cancer Cells Contact Co-Culture}

ASCs were grown to full confluency in 6-well plates at an initial seeding density of $3 \times 10^{5}$ cells per well. $5 \times 10^{4}$ MCF-7 or MDA-MB-231 cells expressing GFP were seeded over the confluent ASCs layer and co-cultures were performed for 5 days (Figure S2C). At the end of the co-culture duration, the cells were either fixed for fluorescent microscopy or trypsinized for counting by FACS or Neubauer chamber. As a control, monocultured confluent ASCs and $5 \times 10^{4}$ MCF-7 or MDA-MB-231 cells cultured for 5 days were trypsinized and pooled together as shown in (Figure S2C) for FACS or Neubauer counting experiments. Monocultured wells were fixed for fluorescent microscopy.

\subsection{GFP Positive Cell Count by FACS}

Following five days of co-culture, ASCs and MCF-7 or MDA-MB-231 cells were trypsinized, washed and resuspended in $500 \mu \mathrm{L}$ PBS/1\%BSA buffer. Monocultured ASCs or MCF-7 or MDA-MB-231 wells were trypsinized, pooled, washed and resuspended in $500 \mu \mathrm{L}$ PBS/1\%BSA buffer. Cells were subjected to flow cytometer (FACS Fortessa, BD, Franklin Lakes, NJ, USA) at a medium aspiration rate and the recording was performed after $20 \mathrm{~s}$ of initial aspiration for $1 \mathrm{~min}$. The number of GFP positive events per minute was counted using FACS Diva software (BD, Franklin Lakes, NJ, USA).

\subsection{CyQUANT Cell Proliferation Assay}

Co-cultured cell proliferation was monitored using CyQUANT proliferation assay (Thermo Fisher Scientific, Waltham, MA, USA) following the manufacturer's protocol. Briefly, following co-culture, the supernatant was removed, and cells were trypsinized and pelleted. The cell pellet was lysed by adding the lysis buffer containing the dye (provided in the kit). Fluorescence was measured in a microplate reader (Tecan, Switzerland) with excitation at $485 \mathrm{~nm}$ and emission detection at $530 \mathrm{~nm}$.

\subsection{Fluorescent Microscopy}

Cells were fixed using $4 \%$ paraformaldehyde for $30 \mathrm{~min}$. Nucleus was stained with DAPI and images were taken using fluorescent microscope and software (Keyence, Itasca, IL, USA).

\subsection{Annexin/Propidium Iodide Live Dead staining}

Annexin/PI live/dead staining was performed using an APC Annexin V Apoptosis Detection Kit with PI (BioLegend, San Diego, CA, USA) following the manufacturer's protocol. Stained cells were analyzed by FACS (FACS Fortessa, BD, Franklin Lakes, NJ, USA) and data were analyzed using FACS Diva software. 


\subsection{Cell Cycle Analyses}

The cell cycle was analyzed by fixing the trypsinized cell with $70 \%$ ice cold ethanol and staining the cells with propidium iodide (Sigma, St. Louis, MO, USA). Cells were analyzed by FACS and data were acquired and analyzed by FACS Diva software.

\subsection{Western Blotting}

Western blotting was performed as published earlier [39]. Blots were developed using primary Phospho-Rb (Ser807/811), p53, p21, beta actin and HRP-linked species-specific secondary antibodies (Cell Signaling Technology, Danvers, MA, USA).

\subsection{Quantitative Real-Time Polymerase Chain Reaction (PCR)}

RNA was extracted from cells using the RNeasy Mini Kit (Qiagen, MD, USA) following the manufacturer's instruction. RNA was reverse transcribed using High Capacity cDNA Reverse Transcription Kit (Applied Biosystems, Foster City, CA, USA) according to manufacturer's protocol. Using cDNA as a template and gene-specific primers (Sigma, St. Louis, MO, USA), the expression of Twist1, Snail1, Snail 2 and CDH2 was quantified by quantitative real time PCR using the QuantStudio 3 Real-time PCR (ThermoFisher Scientific, Waltham, MA, USA). Data for each gene transcript were normalized by calculating the difference $(\Delta \mathrm{Ct})$ from the $\mathrm{Ct}$-housekeeping and $\mathrm{Ct}$-Target genes. The relative increase or decrease in expression was calculated by comparing the reference gene with the target gene $(\Delta \Delta \mathrm{Ct})$ and using the formula for relative expression $(=2 \Delta \Delta \mathrm{Ct})$.

\subsection{Statistical Analyses}

Data are reported as the mean \pm standard error of mean. We assessed the subject variability of the measured outcome. Student's T test and an Analysis of Variance (ANOVA) test were performed where applicable using GraphPad Prism software. Error bars are represented as the mean \pm SEM.

\subsection{Ethics Approval and Consent to Participate}

Adipose tissue from donors undergoing elective plastic surgery procedures at the University of Pittsburgh Medical Center (UPMC) were employed for this study. The procedure of tissue collection was approved by the institutional review board (IRB No.0511186).

\section{Conclusions}

To summarize, our in vitro contact and paracrine co-culture results support the oncological safety of AFT. Future studies should utilize in vivo breast cancer cell titration studies in the presence of lipoaspirates in mice humanized for immune system. Other lines of inquiry might include broader and more rigorous analyses of tumor recurrence among breast cancer patients who received AFT for breast reconstruction. Such data will help to develop conclusive guidelines for the use of AFT for breast reconstruction post-oncological treatment.

List of abbreviations: adipose-derived stem cells (ASCs); autologous fat grafting (AFT); stromal vascular fraction (SVF); retinoblastoma $(\mathrm{Rb})$.

Supplementary Materials: Supplementary materials can be found at http://www.mdpi.com/1422-0067/21/23/9171/ s1. All data generated or analyzed during this study are included in this published article [and its supplementary information files].

Author Contributions: A.E.: conception and design, collection and assembly of data, data analysis and interpretation, manuscript writing; K.S.Y.: collection and assembly of data; K.P.V.: collection and assembly of data; S.C.: collection and assembly of data; L.E.K.: conception and design, data interpretation; J.P.R.: conception and design, data analysis and interpretation, final approval of manuscript. All authors have read and agreed to the published version of the manuscript.

Funding: This study was supported by NCI/NIH Grant R01-CA114246-08A1 to J.P.R. 
Acknowledgments: We acknowledge Kacey G. Marra for her support in data interpretation and manuscript preparation and Louis Dawson from Noun Project for the icon design.

Conflicts of Interest: The authors indicated no potential conflict of interest.

\section{References}

1. Krastev, T.; van Turnhout, A.; Vriens, E.; Smits, L.; van der Hulst, R. Long-term follow-up of autologous fat transfer vs conventional breast reconstruction and association with cancer relapse in patients with breast cancer. JAMA Surg. 2019, 154, 56-63. [CrossRef]

2. Koellensperger, E.; Bonnert, L.C.; Zoernig, I.; Marmé, F.; Sandmann, S.; Germann, G.; Gramley, F.; Leimer, U. The impact of human adipose tissue-derived stem cells on breast cancer cells: Implications for cell-assisted lipotransfers in breast reconstruction. Stem Cell Res. Ther. 2017, 8, 121. [CrossRef]

3. Coleman, S.R. Structural fat grafting. Aesthet. Surg. J. 1998, 18, 386-388. [CrossRef]

4. Tsuji, W.; Valentin, J.E.; Marra, K.G.; Donnenberg, A.D.; Donnenberg, V.S.; Rubin, J.P. An animal model of local breast cancer recurrence in the setting of autologous fat grafting for breast reconstruction. Stem Cells Transl. Med. 2018, 7, 125-134. [CrossRef]

5. Krastev, T.K.; Alshaikh, G.A.; Hommes, J.; Piatkowski, A.; van der Hulst, R.R. Efficacy of autologous fat transfer for the correction of contour deformities in the breast: A systematic review and meta-analysis. J. Plast. Reconstr. Aesthet. Surg. 2018, 71, 1392-1409. [CrossRef]

6. Klinger, M.; Caviggioli, F.; Klinger, F.M.; Giannasi, S.; Bandi, V.; Banzatti, B.; Forcellini, D.; Maione, L.; Catania, B.; Vinci, V. Autologous fat graft in scar treatment. J. Craniofacial Surg. 2013, 24, 1610-1615. [CrossRef] [PubMed]

7. Jaspers, M.E.; Brouwer, K.M.; Van Trier, A.J.; Groot, M.L.; Middelkoop, E.; Van Zuijlen, P.P. Effectiveness of autologous fat grafting in adherent scars: Results obtained by a comprehensive scar evaluation protocol. Plast. Reconstr. Surg. 2017, 139, 212-219. [CrossRef]

8. Juhl, A.A.; Karlsson, P.; Damsgaard, T.E. Fat grafting for alleviating persistent pain after breast cancer treatment: A randomized controlled trial. J. Plast. Reconstr. Aesthet. Surg. 2016, 69, 1192-1202. [CrossRef]

9. Maione, L.; Vinci, V.; Caviggioli, F.; Klinger, F.; Banzatti, B.; Catania, B.; Lisa, A.; Klinger, M. Autologous fat graft in postmastectomy pain syndrome following breast conservative surgery and radiotherapy. Aesthet. Plast. Surg. 2014, 38, 528-532. [CrossRef]

10. Rigotti, G.; Marchi, A.; Galie, M.; Baroni, G.; Benati, D.; Krampera, M.; Pasini, A.; Sbarbati, A. Clinical treatment of radiotherapy tissue damage by lipoaspirate transplant: A healing process mediated by adipose-derived adult stem cells. Plast. Reconstr. Surg. 2007, 119, 1409-1422. [CrossRef]

11. Panettiere, P.; Marchetti, L.; Accorsi, D. The serial free fat transfer in irradiated prosthetic breast reconstructions. Aesthet. Plast. Surg. 2009, 33, 695-700. [CrossRef]

12. Brown, S.A.; Levi, B.; Lequex, C.; Wong, V.W.; Mojallal, A.; Longaker, M.T. Basic science review on adipose tissue for clinicians. Plast. Reconstr. Surg. 2010, 126, 1936-1946. [CrossRef] [PubMed]

13. Rigotti, G.; Marchi, A.; Galie, M.; Baroni, G.; Benati, D.; Krampera, M.; Pasini, A.; Sbarbati, A. Human adipose-derived mesenchymal stromal cells may promote breast cancer progression and metastatic spread. Plast. Reconstr. Surg. 2015, 136, 76-84.

14. Picon-Ruiz, M.; Pan, C.; Drews-Elger, K.; Jang, K.; Besser, A.H.; Zhao, D.; Morata-Tarifa, C.; Kim, M.; Ince, T.A.; Azzam, D.J.; et al. Interactions between adipocytes and breast cancer cells stimulate cytokine production and drive Src/Sox2/miR-302b-mediated malignant progression. Cancer Res. 2016, 76, 491-504. [CrossRef]

15. Charvet, H.J.; Orbay, H.; Harrison, L.; Devi, K.; Sahar, D.E. In vitro effects of adipose-derived stem cells on breast cancer cells harvested from the same patient. Ann. Plast. Surg. 2016, 76, S241-S245. [CrossRef]

16. Goto, H.; Shimono, Y.; Funakoshi, Y.; Imamura, Y.; Toyoda, M.; Kiyota, N.; Kono, S.; Takao, S.; Mukohara, T.; Minami, H. Adipose-derived stem cells enhance human breast cancer growth and cancer stem cell-like properties through adipsin. Oncogene 2019, 38, 767-779. [CrossRef]

17. Balaban, S.; Shearer, R.F.; Lee, L.S.; van Geldermalsen, M.; Schreuder, M.; Shtein, H.C.; Cairns, R.; Thomas, K.C.; Fazakerley, D.J.; Grewal, T.; et al. Adipocyte lipolysis links obesity to breast cancer growth: Adipocyte-derived fatty acids drive breast cancer cell proliferation and migration. Cancer Metab. 2017, 5, 1. [CrossRef] 
18. Jotzu, C.; Alt, E.; Welte, G.; Li, J.; Hennessy, B.T.; Devarajan, E.; Krishnappa, S.; Pinilla, S.; Droll, L.; Song, Y.H. Adipose tissue derived stem cells differentiate into carcinoma-associated fibroblast-like cells under the influence of tumor derived factors. Cell. Oncol. 2011, 34, 55-67. [CrossRef]

19. Rowan, B.G.; Gimble, J.M.; Sheng, M.; Anbalagan, M.; Jones, R.K.; Frazier, T.P.; Asher, M.; Lacayo, E.A.; Friedlander, P.L.; Kutner, R.; et al. Human adipose tissue-derived stromal/stem cells promote migration and early metastasis of triple negative breast cancer xenografts. PLoS ONE 2014, 9, e89595. [CrossRef]

20. Almarzouqi, F.; Rennekampff, H.-O.; Stromps, J.-P.; Alharbi, Z.; Pallua, N. The effect of lipoaspirates vs. dissected abdominal fat on breast cancer cells in vitro. Eur. J. Med. Res. 2017, 22, 10. [CrossRef]

21. Massa, M.; Gasparini, S.; Baldelli, I.; Scarabelli, L.; Santi, P.; Quarto, R.; Repaci, E. Interaction between breast cancer cells and adipose tissue cells derived from fat grafting. Aesthet. Surg. J. 2016, 36, 358-363. [CrossRef]

22. Orbay, H.; Hinchcliff, K.M.; Charvet, H.J.; Sahar, D.E. Fat graft safety after oncologic surgery: Addressing the contradiction between in vitro and clinical studies. Plast. Reconstr. Surg. 2018, 142, 1489-1499. [CrossRef] [PubMed]

23. Silva, M.M.; Kokai, L.E.; Donnenberg, V.S.; Fine, J.L.; Marra, K.G.; Donnenberg, A.D.; Neto, M.S.; Rubin, J.P. Oncologic Safety of Fat Grafting for Autologous Breast Reconstruction in an Animal Model of Residual Breast Cancer. Plast. Reconstr. Surg. 2019, 143, 103-112. [CrossRef]

24. Silva-Vergara, C.; Fontdevila, J.; Descarrega, J.; Burdio, F.; Yoon, T.-S.; Grande, L. Oncological outcomes of lipofilling breast reconstruction: 195 consecutive cases and literature review. J. Plast. Reconstr. Aesthet. Surg. 2016, 69, 475-481. [CrossRef]

25. Lee, J.S.; Eo, P.; Kim, M.C.; Kim, J.B.; Jin, H.K.; Bae, J.S.; Jeong, J.H.; Park, H.Y.; Yang, J.D. Effects of Stromal Vascular Fraction on Breast Cancer Growth and Fat Engraftment in NOD/SCID Mice. Aesthet. Plast. Surg. 2019, 43, 498-513. [CrossRef]

26. Giacinti, C.; Giordano, A. RB and cell cycle progression. Oncogene 2006, 25, 5220-5227. [CrossRef]

27. Shukla, L.; Morrison, W.A.; Shayan, R. Adipose-derived stem cells in radiotherapy injury: A new frontier. Front. Surg. 2015, 2, 1. [CrossRef]

28. Gebremeskel, S.; Gencarelli, J.; Gareau, A.J.; Levatte, T.; Dugandzic, A.; Johnston, B.; Bezuhly, M. Promotion of primary murine breast cancer growth and metastasis by adipose-derived stem cells is reduced in the presence of autologous fat graft. Plast. Reconstr. Surg. 2019, 143, 137-147. [CrossRef]

29. Vahmani, P.; Rolland, D.C.; Gzyl, K.E.; Baines, D.D.; Dugan, M.E. The Growth-Inhibiting Effects of Beef Fatty Acids on MCF-7 Cells Are Influenced Mostly by the Depot Location and Inconsistently by the Biohydrogenation Intermediate Content. Lipids 2018, 53, 699-708. [CrossRef]

30. Fain, J.N.; Cheema, P.; Madan, A.K.; Tichansky, D.S. Dexamethasone and the inflammatory response in explants of human omental adipose tissue. Mol. Cell. Endocrinol. 2010, 315, 292-298. [CrossRef]

31. Gesta, S.; Lolmède, K.; Daviaud, D.; Berlan, M.; Bouloumié, A.; Lafontan, M.; Valet, P.; Saulnier-Blache, J.S. Culture of human adipose tissue explants leads to profound alteration of adipocyte gene expression. Horm. Metab. Res. 2003, 35, 158-163. [CrossRef]

32. Harms, M.J.; Li, Q.; Lee, S.; Zhang, C.; Kull, B.; Hallen, S.; Thorell, A.; Alexandersson, I.; Hagberg, C.E.; Peng, X.-R.; et al. Mature human white adipocytes cultured under membranes maintain identity, function, and can transdifferentiate into brown-like adipocytes. Cell Rep. 2019, 27, 213-225. [CrossRef]

33. Mazur, S.; Zołocińska, A.; Siennicka, K.; Janik-Kosacka, K.; Chrapusta, A.; Pojda, Z. Safety of adipose-derived cell (stromal vascular fraction-SVF) augmentation for surgical breast reconstruction in cancer patients. Adv. Clin. Exp. Med. 2018, 27, 1085-1090. [CrossRef]

34. Ritter, A.; Friemel, A.; Fornoff, F.; Adjan, M.; Solbach, C.; Yuan, J.; Louwen, F. Characterization of adipose-derived stem cells from subcutaneous and visceral adipose tissues and their function in breast cancer cells. Oncotarget 2015, 6, 34475. [CrossRef]

35. Ryu, H.; Oh, J.E.; Rhee, K.J.; Baik, S.K.; Kim, J.; Kang, S.J.; Sohn, J.H.; Choi, E.; Shin, H.C.; Kim, Y.M.; et al. Adipose tissue-derived mesenchymal stem cells cultured at high density express IFN- $\beta$ and suppress the growth of MCF-7 human breast cancer cells. Cancer Lett. 2014, 352, 220-227. [CrossRef]

36. Yoon, N.; Park, M.; Shigemoto, T.; Peltier, G.; Lee, R. Activated human mesenchymal stem/stromal cells suppress metastatic features of MDA-MB-231 cells by secreting IFN- $\beta$. Cell Death Dis. 2016, 7, e2191. [CrossRef]

37. Sherr, C.J.; McCormick, F. The RB and p53 pathways in cancer. Cancer Cell 2002, 2, 103-112. [CrossRef] 
38. Cavinato, M.; Koziel, R.; Romani, N.; Weinmüllner, R.; Jenewein, B.; Hermann, M.; Dubrac, S.; Ratzinger, G.; Grillari, J.; Schmuth, M. UVB-Induced Senescence of Human Dermal Fibroblasts Involves Impairment of Proteasome and Enhanced Autophagic Activity. J. Gerontol. Ser. A 2017, 72, 632-639. [CrossRef]

39. Ejaz, A.; Mitterberger, M.C.; Lu, Z.; Mattesich, M.; Zwierzina, M.E.; Hörl, S.; Kaiser, A.; Viertler, H.-P.; Rostek, U.; Meryk, A. Weight loss upregulates the small GTPase DIRAS3 in human white adipose progenitor cells, which negatively regulates adipogenesis and activates autophagy via Akt-mTOR inhibition. EBioMedicine 2016, 6, 149-161. [CrossRef]

Publisher's Note: MDPI stays neutral with regard to jurisdictional claims in published maps and institutional affiliations.

(C) 2020 by the authors. Licensee MDPI, Basel, Switzerland. This article is an open access article distributed under the terms and conditions of the Creative Commons Attribution (CC BY) license (http://creativecommons.org/licenses/by/4.0/). 